\title{
Everyone, Everywhere, Every Time
}

\author{
Clayton A. Copeland \\ University of South Carolina
}

\begin{abstract}
The University of South Carolina's Knowledge School has a commitment. The commitment: Everyone. Everywhere. Every time. The "Knowledge School" is about empowerment. It is about accessing abilities in everyone. It is about using abilities to ensure knowledge creation. And it is about using abilities to ensure equity. This chapter defines a philosophy rooted in tenets of universal access and design. It then highlights several initiatives in teaching, research, and service that put the philosophy into action.
\end{abstract}

Keywords: accessibility, disability, universal access, universal design



This is an Open Access article distributed under the terms of the Creative Commons Attribution 4.0 International License (http://creativecommons.org/licenses/by/4.0), which permits unrestricted use, distribution, and reproduction in any medium, provided the original work is properly cited. 
The journey to the University of South Carolina's "Knowledge School" is a journey of countless and continuing steps, a journey that would not have begun and could not continue without steadfast determination and the culmination of individual journeys, passions, and "callings" to areas of emphasis and research. It could not have begun and could not continue without a joint "calling" to do good in the world, to make important differences for as many people as possible and for as long as possible. Being the "Knowledge School" is about empowerment. It is about awakening the individual abilities within each person who comes to know this place, this philosophy, these values. It is about accessing abilities. It is about using abilities to ensure knowledge creation. And it is about using abilities to ensure equity. As Kaitlin Scott, a recent alum of our program so aptly said when asked to define Universal Access and Design, tenets of our program, "It is about Everyone, Everywhere, Every time."

In The Future of Success, former Secretary of Labor Robert Reich directs attention to a compelling issue: the need for a civic model where success is no longer measured in terms of personal acquisition and financial achievement. His solution is to frame accomplishments in terms of "spiritual grounding, the richness of our relationships, the sturdiness of our families, and the character of our communities" (Reich, 2002, p. 248). Although this still resonates with most Americans, we are still familiar with the "sorting" processes that Reich brings to mind when speaking of the divisive factors hindering community cohesiveness. Many of the factors, including income, education, employment, access to health care, and housing opportunities, consistently receive the attention of policy makers. Literacy, in its many forms, and equity of access to information appear less frequently in policy discussions, but they are also critical sorting factors that bind and separate members of communities and the opportunities available to them. 
The power of cultural institutions, such as libraries and museums, to promote literacy and shared civic engagement has been obvious for decades (Rose, 1917; Anastasiades, 1999). This power grows as these organizations integrate their collections, form partnerships, and capitalize upon new technologies and shared facilities. There are now many exemplary projects blurring the lines between cultural institutions and providing high caliber interactive learning environments. But the true impact of these and similar projects are limited and even preferential if some individuals are excluded by another, perhaps less obvious sorting mechanism: factors that make them inaccessible to people with disabilities, or to those whose abilities are considered fundamentally different from others in the larger community.

Libraries and cultural heritage institutions have long been established as great equalizers of knowledge. In his works, however, R. David Lankes asserts, "The vision for a new librarianship must go beyond finding library-related uses for information technology and the Internet; it must provide a durable foundation." (Lankes, 2011, n.p.) Lankes further argues, "to thrive, communities need libraries that go beyond bricks and mortar, and beyond books and literature. We need to expect more out of our libraries. They should be places of learning and advocates for our communities in terms of privacy, intellectual property, and economic development." (Lankes, 2012, n.p.) In essence, libraries and librarians serve as an axis for their communities. These organizations are challenged to meet the demand for equity of access to information through Universal Design (UD), Universal Access, and inclusion, in both physical and digital environments. Though contextualized within Higher Education, Burgstahler (2015) identifies two possible modes of access (and use): The Accommodation Approach and Proactive Approaches to Access. The Accommodation Approach is grounded in a medical or "deficit" model of disability, "in which a professional identifies an individual's limitations or Journal of New Librarianship, 4(2019) pp. 380-386 10.21173/newlibs/7/10 
'deficits' and describes a cure, rehabilitation, or adjustment that allow this person to fit into an established environment or use an existing product” (p.9). Negatives result from this model, some of which include the following, as asserted by Burgstahler (2015), p. 10-11):

the process for securing accommodations marginalizes [the population] by requiring a segregated process for gaining access; an accommodation does not always result in content and experiences equivalent to those of other students; accommodations can create an unnecessary dependency [on a student service office]; the value associated with an accommodation does not extend to [students with disabilities] who choose not to self-disclose nor other [students in a class] who might benefit; an accommodation for one student does not in and of itself make [a course] or other offering more accessible to students in the future. Whereas accommodation is a reactive approach to provide access to an individual, proactive approaches, including Barrier-free and Accessible Design, Usable Design, and Universal Design, strive to ensure access to a potential audience with a wide range of characteristics.

An expanding body of research indicates substantial barriers to equitable access to information. The inaccessibility of physical and digital information environments and services has a disproportionate impact on populations with disabilities, including their access to public health services, education resources, and employment opportunities. To date, there are few extended educational or training opportunities that focus on removing these barriers in library environments and little empirical research that relates the lived experiences of these marginalized populations to the design of better and more inclusive experiences (Copeland $2011 ; 2012)$.

The School of Library and Information Science (SLIS) at the University of South Carolina, the "Knowledge School" has a commitment. It has a commitment to people. It has a commitment to a school of thought and a social mission of inclusion. We have a commitment to "diversity by design" (Dali and Keren, 2018), or to the idea that diversity and inclusion are integral to our work. We further assert that the work of libraries and information organizations 
cannot happen without including everyone, everywhere, every time. We are on a mission. Our first commitment is to Library and Information Science (LIS) students, for through their work and their contributions to each of their communities, they are the future of this mission. They play a deterministic role not only in the future of libraries, cultural heritage institutions, and information access, but in the lived experiences of the people in their communities. We believe they have the power to play a deterministic role in this larger social mission of inclusion, in the impact that inclusion has on knowledge creation, in the impact that knowledge creation has on society itself.

What does this mean for the "Knowledge School"? We are continually strategizing and working with a purpose of integrating principles of equity, diversity, and inclusion throughout the curriculum. Through intensive study and investigatory work with partnering organizations, our students become embedded researchers and service learners. The examples herein are just a few of the embedded learning opportunities for "Knowledge School" students.

- In our Foundations course, Introduction to Library and Information Science, students are immediately thrust into immersive learning experiences in which they explore the information sector and conduct in-depth interviews and observations with diverse information organizations and the professionals representing them. Students are introduced to concepts of diversity, inclusion, and social constructivism. They analyze the power of social constructions (such as ability or disability) and then are tasked with strategizing specific plans of action for dispelling myths, for deconstructing systems that promote inequities, and for enacting inclusive policies and practices. 
- In Introduction to Information Technologies, students build upon their foundational knowledge of universal Access and Universal Design. They partner, either formally or informally, with a library or information organization. Over the course of a semester, they conduct both a community analysis (comprised of an inner and outer analysis of the information organization and the communi(ties) it serves, and a needs analysis. Based upon the results of these analyses, they apply their emerging skills with database and web searching to better understand identified barriers to information access and use. The experience culminates with an equipment proposal for a universally accessible computer/technology workstation. The workstation must include hardware, software, and furnishings resulting in a workstation that adheres to principles of Universal Design.

- In a number of other courses, including Libraries, Literacy, and Literature, Materials and Programming for Children and Youth with Disabilities, and Planning Library Facilities course, the students again become embedded researchers. While engaged in service learning and field work, they conduct community and needs analyses for their partnering libraries/information organizations. In Libraries, Literacy, and Literature, these analyses pertain to multiple literacies (information, technology, media, multicultural, etc.). In Materials and Programming for Children and Youth with Disabilities, these analyses pertain to collection development and inclusive programming and services. Each course results, respectively, in the design and implementation a responsive program or service that adheres to principles of Universal Design and puts Universal Design for Learning into action. In Planning Library Facilities, students design a building program for a new-build or 
the remodel for all or part of a facility to ensure that, in addition to adhering to other standards of excellence, the facility integrates principles of universal design. As these examples may begin to indicate, the "Knowledge School" has a commitment to understanding the lived experience and to promoting libraries as community anchors. We have a commitment to then then using the lived experience to understand social constructions, and to using this information to discover innovative solutions to identified barriers to knowledge creation. To that end, SLIS has also established the Laboratory for Leadership in Equity and Diversity (SLIS_LLEAD), a new and innovative laboratory to conduct research, provide resources, and plan programming related to protecting access to information people need. Areas and issues of interest include: Universal access and design; the Digital Divide; Freedom to Read; Information Access Policies; Access for people with different abilities; Electronic, web, and mobile accessibility; Inclusion and Diversity Policies; Preservice and Continuing Education; and Skills development and job training. Specific initiatives currently include:

- Development of an innovative protocol instrument to assess Universal Design (UD) and the user experience in libraries. Improved, accessible, and inclusive library programming and services based on principles of Universal Access and Design and informed by the lived experiences of people with disabilities;

- Awareness of the value created libraries act as strong community anchors that promote accessibility and inclusion and create educational, employment, and economic opportunities;

- More complete and accurate public characterizations of library accessibility using an expanded set of tools and reliable metrics; 
- Increased national interest in the relationship between library services for diverse, differently-able, and disenfranchised populations; community engagement; educational and employment opportunities; and economic growth and development.

\section{References}

Anastasiades, S., \& Seton Hall University. (1999). John Cotton Dana and the mission of the Newark museum, 1909-1929. South Orange, N.J: Seton Hall University.

Burgstahler, S. (2015). Universal design in higher education: From principles to practice.

Copeland, C.A. (2012). Equity of access to information: A comparative exploration of library accessibility and information access from differently-able patrons' perspectives. Doctoral Dissertation. University of South Carolina, Columbia, SC.

Copeland, C.A. (2011). Library and information center accessibility: The differently-able patron's perspective. Technical Services Quarterly, 28(2), p. 223-241, DOI: 10.1080/07317131.2011.546281

Lankes, R. D. (2011). The Atlas of New Librarianship.

Lankes, R. D. (2012). Expect more: Demanding better libraries for today's complex world. Place of publication not identified: R. David Lankes.

Reich, R. B. (2002). The future of success: Working and living in the new economy. New York: Vintage Books

Rose, E. (1917). Bridging the gulf: Work with the Russian Jews and other newcomers. New York: Immigrant publication society, incorporated. 